\title{
Information Resources Usage in Project Management Digital Learning System
}

\author{
Nitza Davidovitch ${ }^{1}$, Margarita Belichenko ${ }^{1,2} \&$ Yurii Kravchenko ${ }^{1,2}$ \\ ${ }^{1}$ Behavioral Sciences Department, Ariel University, Ariel, Israel \\ ${ }^{2}$ Faculty of Information Technology, Taras Shevchenko National University of Kyiv, Ukraine \\ Correspondence: Nitza Davidovitch, Behavioral Sciences Department, Ariel University, Ramat HaGolan Str., 28, \\ Ariel, Israel. Tel: 972-54-693-8987. E-mail: d.nitza@ariel.ac.il
}

\author{
Received: November 12, $2016 \quad$ Accepted: December 20, $2016 \quad$ Online Published: January 9, 2017 \\ doi:10.5539/jel.v6n2p146 \\ URL: http://dx.doi.org/10.5539/jel.v6n2p146
}

\begin{abstract}
The article combines a theoretical approach to structuring knowledge that is based on the integrated use of fuzzy semantic network theory predicates, Boolean functions, theory of complexity of network structures and some practical aspects to be considered in the distance learning at the university. The paper proposes a methodological approach that takes into account these features. The paper deals with the structuring of project management programs of academic mobility. The features of these projects show their impact on the progress and results of the implementation.

It is shown that traditional approaches to solving the problems of academic mobility management applications to integrate the process of setting objectives and planning projects. But due to the complexity of academic mobility programs to solve these problems effectively without decomposing it into components can be managed quite difficult. Therefore, the main idea of this paper is that an increasing the efficiency of the university on the basis of a possible application of rational structuring of academic mobility programs. The features of these projects shows their impact on the progress and results of their implementation and the ways of construction of project management Digital learning systems.

The experience of universities of many countries shows that an effective tool to overcome these obstacles is Digital learning, which allows to get all necessary knowledge at any time and in any place. The identity of urgency takes in terms of academic mobility when students and teachers work in another country. The paper presents the analyse of the structure of scientific and methodological basis of project management systems. The model determines the effect of academic mobility project management tools through knowledge of business administration at the progress of the educational projects. In this structure are identified two parts: creation tool to identify knowledge users and how they change, and the creation of information tools effect on these people.
\end{abstract}

Keywords: information interaction, digital learning, knowledge, project management, higher education

\section{Introduction}

Education today has become a sector that is developing rapidly in today's information era. University is a center of education, science and culture, which provides studies at certain levels of higher education, conducts scientific, technical, and methodological innovation activities and provides individuals obtaining higher education according to their vocation, interests and abilities. The main task of university preparation of experts became to able to work effectively in an environment characterized by a high degree of diversity, global relationships, access to digital information and high dynamic. However, most universities also need to learn to work and survive in the new competitive market. The end of the last century for universities was marked by a number of radical changes: a decrease in public investment, increasing criticism of the structure of academic management, increasing cost of education, there is a need for new methods of accounting of financial support, the development of information and communication technologies, competition from the commercial sector of education, the growing international mobility of students and teachers, expansion of export of educational programs and services. All these changes have forced universities to review their strategic goals and decide on the need for reform and change management approaches to education and research activities. 
In modern society, the project team management becomes more and more important as an effective team can perform more tasks in a shorter periods thanks to coordinated work of all team members. These results can be obtained by conflict reducing and increasing trust between project team members through non-forceful influences, which are aimed at creating a common, unifying picture of the world for the whole team.

There is a need in research and applying of new non-forceful mechanisms influencing the project team to obtain the necessary results.

\section{Theoretical Background}

Project is devoted to a significant number of scientific papers. It pays considerable attention to the creation of project management at universities, methods of program planning and others. The scientific and methodological tools of project management, which can be applied in academic mobility programs.

Study the effectiveness of management of universities in the information society, the main characteristic feature of permanent transformation and a progressive accumulation of knowledge, dedicated many works mostly foreign scientists, including university as a business organization is seen in the works of Clark, Ropke, Haynutdynova, Hrudzynsky, Tsatouryan, Romanovsky, Gavrilyuk, Roznova. The question of process-oriented and project management investigated Flint, Asaulom, Goryunov, Wagner, Kaparov, Kudryavtsev, Sukhorukov, Fedorkin, Strongina, Afasizhevym, Teshevym, Grigno, Lankin, Belyakin. In most studies the problems of adaptation and survival of the university, as subjects of a competitive market, changing economic conditions (Ramirez, 2014). However, solutions to new challenges of universities require practical developments in the field of university management, including the development of innovative management structure capable of ensuring the efficiency and development of universities in terms of autonomy, fierce competition, the variability of the environment and the lack of experience of entrepreneurship. One of the major problems in the projects and programs management of is the task of evaluating the status of the product of the project, project environment and surrounding. The basis for effective project management is information. In this case actual information timely receipt is more necessary, that is difficult due to the highly dynamics of processes in projects. And the information is "getting old" in projects quicker than in operating activity. If the information is complete, timely, accurate, we can believe in the success of the project.

\section{Problem Statement}

The theoretical justification developed the concept of using information resource distance learning system is faced with the following challenges. Thus, it is necessary to find such structure of information resources $\left\{V^{*} \cap D^{*}\right\} \in \Omega^{*}$ in which the quality of learning would meet the set requirements and the training and the cost decreased.

The hypothesis of an effective information resource structuring of Digital learning system:

The theoretical problem: immerse a set $\Omega$ to such as its subset $\Omega^{*} \subseteq \Omega,|\Omega| \geq\left|\Omega^{*}\right|$ for which the objective function of quality learning $E\left(V^{*} \cap D^{*}, F_{i n}^{E}, F_{o n}^{E}\right)$ no worse than necessary $E_{*}$; the training time $T\left(V^{*} \cup D^{*}, F_{i n}^{T}, F_{o n}^{T}\right)$ and seeks to minimize the costs of establishing the system and its operation $C\left(V^{*} \cup D^{*}, F_{i n}^{C}, F_{o n}^{C}\right)$ also seeks to minimum significance.

$$
\left\{V^{*} \cap D^{*}\right\} \in \Omega^{*}, \Omega^{*} \subseteq \Omega,|\Omega| \geq\left|\Omega^{*}\right|:\left\{\begin{array}{l}
E\left(V^{*} \cup D^{*}, F_{i n}^{E}, F_{o n}^{E}\right) \geq E_{*} \\
T\left(V^{*} \cup D^{*}, F_{i n}^{T}, F_{o n}^{T}\right) \rightarrow \min \\
C\left(V^{*} \cup D^{*}, F_{i n}^{C}, F_{o n}^{C}\right) \rightarrow \min
\end{array},\right.
$$

where: 
$\left\{v_{j}^{*}\right\} \in V^{*}$ — set of elements of the model information resource;

$\left\{d_{k}^{*}\right\} \in D^{*}$ - set of links between elements of the model information resource;

$j, k \in N$-natural numbers;

$\Omega$-information resources;

$\Omega^{*}$-model of information resource;

$E\left(V^{*} \cup D^{*}, F_{i n}^{E}, F_{o n}^{E}\right)$-objective function of education quality;

$T\left(V^{*} \cup D^{*}, F_{i n}^{T}, F_{o n}^{T}\right)$-time of training;

$C\left(V^{*} \cup D^{*}, F_{\text {in }}^{C}, F_{\text {on }}^{C}\right)$-costs of establishing the system and its operation;

$E_{*}$ - specified importance to the quality of education;

$F_{i n}^{E}, F_{o n}^{E}, F_{i n}^{C}, F_{o n}^{C}, F_{i n}^{T}, F_{o n}^{E}$-internal and external factors affecting according to the quality, cost and training time.

The essence of the conflicting requirements for modeling information resource consists in the following:

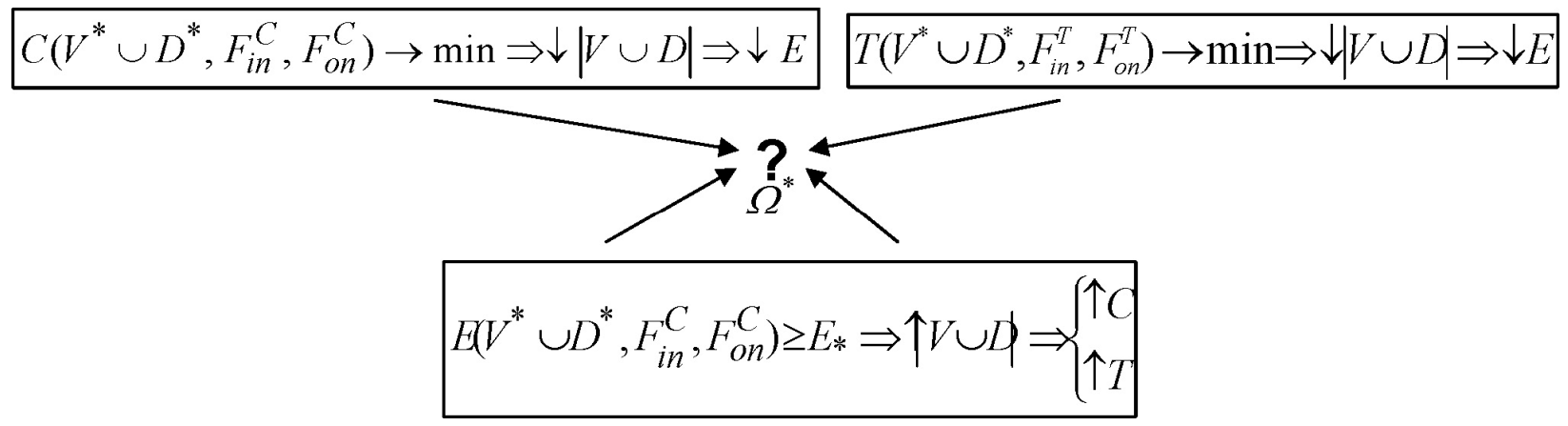

Figure 1. The mathematical formalization of conflicting requirements

We pay attention to of the fact that to receive analytical or algorithmic dependence.

$E\left(V^{*} \cup D^{*}, F_{i n}^{E}, F_{o n}^{E}\right) ; T\left(V^{*} \cup D^{*}, F_{i n}^{T}, F_{o n}^{T}\right) ; C\left(V^{*} \cup D^{*}, F_{i n}^{C}, F_{o n}^{C}\right)$, is not possible because of complexity of the studied process. It is proposed the following research hypothesis: the quality of the learning process will increase training time and costs are reduced on condition of a simple presentation of educational material (information resource), and a minimum of loss in the process of structuring upon presentation in the digital learning (2). 


$$
\left.\begin{array}{l}
E\left(V^{*} \cup D^{*}, F_{i n}^{E}, F_{o n}^{E}\right) \geq E_{*} \\
T\left(V^{*} \cup D^{*}, F_{i n}^{T}, F_{o n}^{T}\right) \rightarrow \min \\
C\left(V^{*} \cup D^{*}, F_{\text {in }}^{C}, F_{o n}^{C}\right) \rightarrow \min
\end{array}\right\} \Leftarrow\left\{\begin{array}{l}
\left|\Omega^{*}\right| \leq|\Omega| \\
|\Omega|-\left|\Omega^{*}\right| \rightarrow \min . \\
S l\left(\Omega^{*}\right) \rightarrow \min
\end{array}\right.
$$

Where $\operatorname{Sl}\left(\Omega^{*}\right)$-indicator of complexity of the information resource.

In this case, the scientific problem (1.1) takes the following mathematically formalized form (Figure 2).

\section{SCIENTIFIC PROBLEM}

$$
\Omega^{*} \subset\left(V^{*} \cap D^{*}\right):\left\{\begin{array}{l}
S l\left(\Omega^{*}\right) \rightarrow \min \\
|\Omega|-\left|\Omega^{*}\right| \rightarrow \min \\
\left|\Omega^{*}\right| \leq|\Omega|
\end{array}\right.
$$

\section{Contradiction between the requirements}

$$
S l\left(\Omega^{*}\right) \rightarrow \min \Rightarrow|\Omega|-\left|\Omega^{*}\right| \downarrow \stackrel{\Omega}{\longrightarrow} \Rightarrow\left|\Omega^{*}\right| \rightarrow \min \Rightarrow S l\left(\Omega^{*}\right) \uparrow
$$

Figure 2. The scientific problem

This conditioned that structure as a set of plural elements and plural links (relations) between them can be analytically evaluated in terms of complexity and therefore transfer problem in the the plane of the complexity theory. Specifically, it is necessary to structure the information resource in such way that complexity of the resulting structure was minimal, with its negligible decreasing. In other words, to teach simply, without unnecessary complication of educational material $\left(S l\left(\Omega^{*}\right) \rightarrow \min \right)$, and minimize the loss of knowledge.

\section{Development of Mathematical Models of Knowledge Presentation in Distance Learning System}

Suppose that set N-heterogeneous semantic network $S=(V, D, \Gamma)$, where $V$-the set of concepts network capacity $|V|=n ; D$-the set of arcs. 


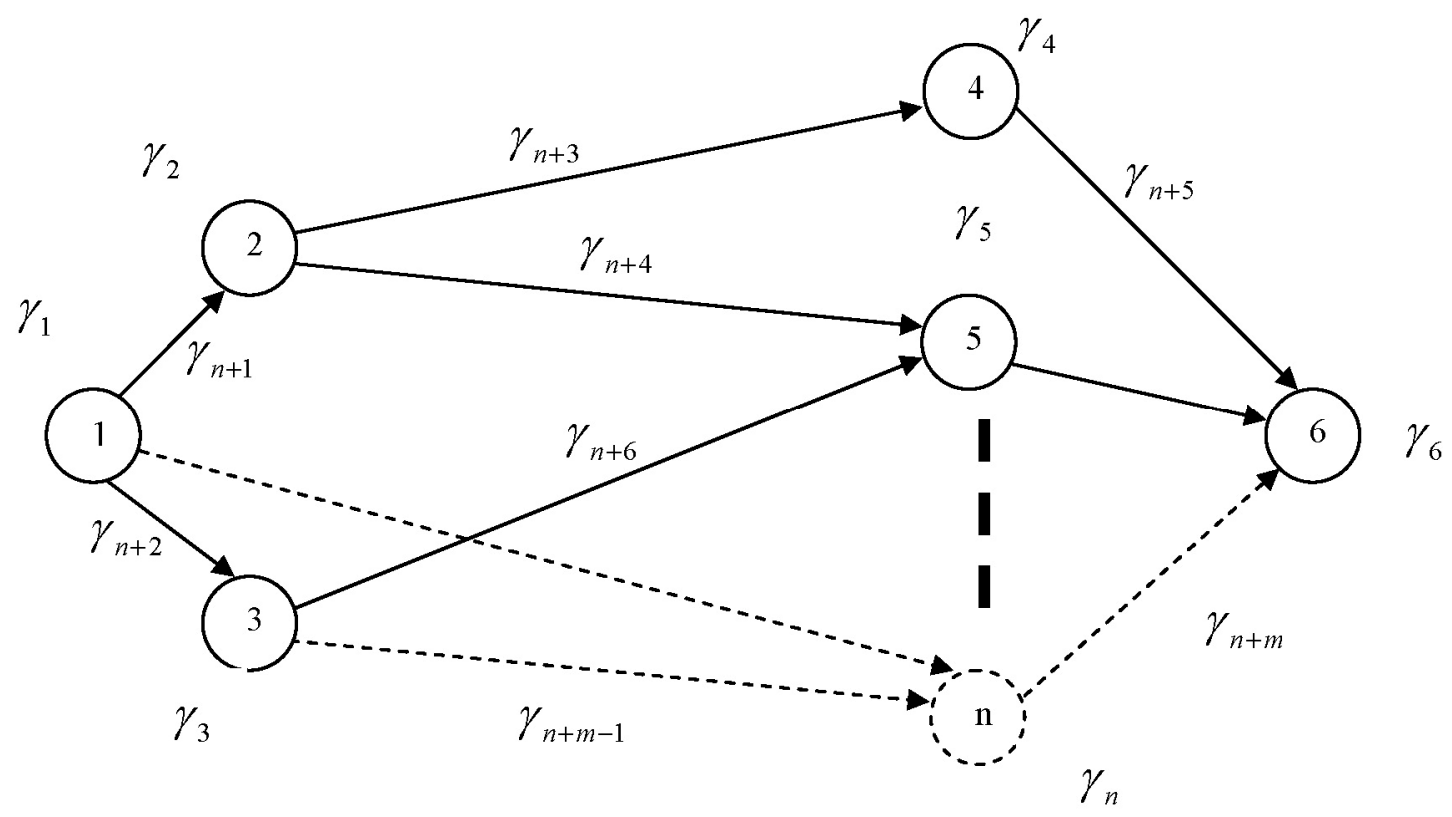

Figure 3. N-heterogeneous semantic network

$S=(V, D, \Gamma)$ (Relations between concepts) network capacity $|D|=m ; \Gamma=\left(\Gamma_{V}, \Gamma_{D}\right)$-the set of scales of vertices and arcs of network under capacity $|\Gamma|=\left|\Gamma_{V} \cup \Gamma_{D}\right|=n+m, \quad n, m \in N$, $\gamma_{i} \in \Gamma_{V}, i=\overline{1, n} ; \gamma_{j} \in \Gamma_{D}, j=\overline{n+1, m}$ (Figure 3).

The modern theory of laden digraphs is developed for the case when $|\Gamma|=\left|\Gamma_{D}\right|=m, \quad m \in N$, that takes into account only the weight of arcs, and $\Gamma_{V}=\varnothing$. Thus, there is theoretical problem of mathematical formalization N- heterogeneous semantic network $S=(V, D, \Gamma)$.

Following approach is proposed for resolving this problem. We introduce the concept of "elementary semantic network of the 1st rank", as the network of the two vertices and arc between them with appropriate weights (Figure 4).

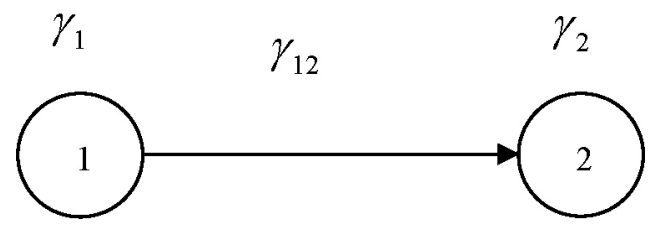

Figure 4. Elementary semantic network of the 1 st rank

Then, it is logical to introduce the concept "given elementary semantic network of the 1st sort" the weight of the $\operatorname{arc} \gamma$, which corresponds to elementary semantic network of the 1st rank (Figure 5). 


$$
\gamma=\Theta_{k}\left(\gamma_{1}, \gamma_{2}, \gamma_{12}\right) \equiv m, \quad m^{T}=\left(m_{0}, m_{1}\right)
$$

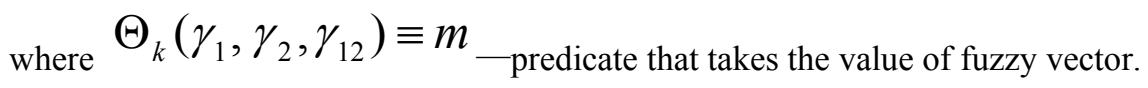

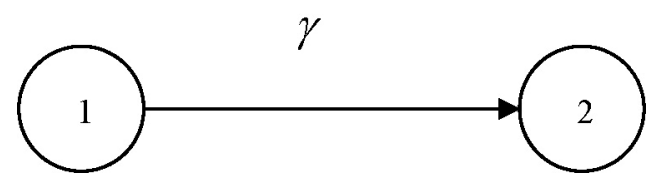

Figure 5. Present the elementary semantic network of the 1 st rank

It is obvious that a network of (Figure 5) obtained after transformation of network (Figure 4). The area of predicate is expanded from the traditional 0 or 1 to fuzzy logic two-component vector $m_{i j k}^{T}=\left(m_{0 i j k}, m_{1 j i k}\right)$, in this case if $m_{i j k}^{T}=(0,1)$, then the vector is set to "true", and if $m_{i j k}^{T}=(1,0)$, then-"false".

Also the implementation should be provided:

$$
0 \geq m_{0 i l k}, m_{1 i k \geq} 1, m_{0 i j k}+m_{0 i l k}=1 .
$$

Objections of vector $\overline{m_{i j k}}$ corresponds the rearrangement of its elements $\bar{m}_{i l k}^{T}=\left(m_{1 i j k}, m_{0 i l k}\right)$. The measure of of fuzziness logical vector $m_{i l k}$ is the entropy $S\left(m_{i j k}\right)=-m_{0 i j k} \log _{2} m_{0 i j k}-m_{1 i l k} \log _{2} m_{1 i j k}$. The measure of of fuzziness semantic network is the value $S(M)=\sum_{i, j} S\left(m_{i j k}\right)$, де $m_{i j k} \in M, i=\overline{1, l}$, $j=\overline{1, c}, i, j \in N$

Every logical operation between vector variables is compared tensor 3rd rank. This tensors preserve the appearance that they were in a vector representation of traditional precise logic. It allows unambiguously describe operations with fuzzy logic variables. In addition, between operations remain the same bonds that took place in precise logic. A significant convenience of vector representation is that operations on logical variables can be presented in matrix form. The proposed approach differs from the existing theory of fuzzy predicates so that instead of the value of fuzzy predicate vector is associated with a fuzzy semantic network. This has allowed in the logical conclusions to combine the advantages of the predicates theory, variable of logic vector representation and matrix theory.

We introduce the concept of "the elementary semantic network 2-rank" (Figure 5) $S=(V, D, \Gamma),|V|=n$, $|D|=m,|\Gamma|=\left|\Gamma_{V} \cup \Gamma_{D}\right|=n+m, \quad n, m \in N$, a network that a result of the in changes (3), (4) may become so-called "a present elementary semantic network 2-rank" $S^{*}=\left(V^{*}, D^{*}, \Gamma^{*}\right)$, which

$$
|V|>\left|V^{*}\right|>2 ; \quad|D|>\left|D^{*}\right|>1 ; \quad|\Gamma|>\left|\Gamma^{*}\right|>3
$$




\section{Conclusion}

The article combines a theoretical approach to structuring knowledge that is based on the integrated use of fuzzy semantic network of the theory of predicates, Boolean functions, theory of complexity of network structures and practical aspects that need to be considered in the digital learning management at classical university.

Thus, the proposed approach has allowed to solve the problem of theoretical mathematical formalization of Nheterogeneous semantic network. The most promising, in our opinion, is developed model that combines the advantages of theories of predicates fuzzy logic and semantic networks.

Definition (3). Suppose variables $\gamma_{1}, \gamma_{2}, \ldots, \gamma_{n+m}$ take values that are arbitrary sets: $\gamma_{i} \in \Gamma_{V}, i=1,2, \ldots, n$, $\gamma_{j} \in \Gamma_{D}, j=n+1, n+2, \ldots, m$, then the function $y=\Theta\left(\gamma_{1}, \gamma_{2}, \ldots, \gamma_{n+m}\right)$, which can be placed in accordance the fuzzy semantic network $S=(V, D, \Gamma)$, that $\Theta\left(\gamma_{1}, \gamma_{2}, \ldots, \gamma_{n+m}\right) \equiv S$, where $\mathrm{V}$ - the set of concepts of network capacity $|V|=n$; D-the set of arcs (relations between concepts) network capacity $|D|=m ; \Gamma=\left(\Gamma_{V}, \Gamma_{D}\right)$-the set of scales of vertices and arcs of network in accordance, capacity $|\Gamma|=\left|\Gamma_{V} \cup \Gamma_{D}\right|=n+m, \quad n, m \in N$, $\gamma_{i} \in \Gamma_{V}, i=\overline{1, n} ; \quad \gamma_{j} \in \Gamma_{D}, j=\overline{n+1, m}$ is called: $\mathrm{n}+$ m-predicates on fuzzy semantic network.

Because any the fuzzy semantic network $S=(V, D, \Gamma)$ can be represented as a digraph laden basic semantic network 2 rank, then the above network can be described in one and only one adjacency matrix $M$. Thus, mathematical formalization of the statement has the form:

$$
\begin{array}{r}
\forall \gamma_{i} \in V, i=\overline{1, n}, \gamma_{j} \in D, j=\overline{n+1, m} \Rightarrow \exists \\
\Theta_{k}\left(x_{1}, x_{2}, \ldots, x_{m}\right) \equiv\|\| \begin{array}{cccc}
m_{11 k} & m_{12 k} & \ldots & m_{1 c k} \\
m_{21 k} & m_{22 k} & \ldots & m_{21 k} \\
\vdots & & \ldots & \vdots \\
m_{l 1 k} & m_{l 2 k} & \ldots & m_{l c k}
\end{array} \| .
\end{array}
$$

The area of values contiguity of matrix elements are extended from the traditional 0 or 1 to fuzzy logic two-component vector $m_{i j k}^{T}=\left(m_{0 i j k}, m_{1 i j k}\right)$.

So fuzzy predicate logic is developed in vector-matrix representation. Predicate represented as a vector field fuzzy of variables of a given terms set. We investigate operations above predicates, develop a variant of fuzzy inference based on rules defined as relations between predicates. Let us define the definition and calculation method of fuzzy quantifiers $\forall$ й $\exists$.

Considered above scheme of fuzzy predicates in vector-matrix representation allows us to introduce logic operations without arbitrary assumptions. Logical operations on fuzzy variables are described by the same tensor, as in "a strict" logic. The result is a flexible and reasonable system of calculations containing empirical expert assessments only "input" of algorithms.

\section{References}

Altbach, P. G. (2007). Introduction: The underlying realities of higher education in the 21 st century. In P. G. Altbach, \& P. M. Peterson (Eds.), Higher education in the new century: Global challenges and innovative ideas. Rotterdam/Taipei: Sense Publishers.

Altbach, P. G., Reisberg, L., \& Rumbley, L. E. (2009). Trends in global higher education: Tracking an academic revolution. Report prepared for the UNESCO2009 World Conference on Higher Education, Paris: United National Educational, Scientific, and Cultural Organization. 
Becker, R., \& Kolster, R. (2012). International student recruitment: Policies and developments in selected countries. Netherlands: Nuffic.

Bhandari, R., \& Blumenthal, P. (2013). International students and global mobility in higher education: National trends and new directions. International Studies.

Bridges, D., Juceviciene, P., Jucevicius, R., Mclaughlin, T. H., \& Stankeviciute, J. (Eds.). (2014). Higher education and national development: Universities and societies in transition. London: Routledge.

Bushuyev, S., \& Bushueva, N. (2010). Project Management. Fundamentals of professional knowledge and competence assessment system of project managers (National Competence Baseline, NCB UA Version 3.1).

Choudaha, R., \& Chang, L. (2012). Trends in international student mobility. New York: World Education Services. Retrieved from http://www.uis.unesco.org/Library/Documents/research-trends-international-student-mobility-education-20 12-en.pdf

Deem, R., Mok, K. H., \& Lucas, L. (2008). Transforming higher education in whose image? Exploring the concept of the "World Class University" in Europe and Asia. Higher Education Policy, 21, 83-97. https://doi.org/10.1057/palgrave.hep.8300179

Dirlik, A. (2012). Trans nationalization and the university: The perspective of global modernity. Boundary 2, 39(3), 47-73. https://doi.org/10.1215/01903659-1730617

Dobbins, M., \& Knill, C. (2014). Higher education governance and policy change in Western Europe. https://doi.org/10.1057/9781137399854

Dobbins, M., Knill, C., \& Vögtle, E. M. (2011). An analytical framework for the cross-country comparison of higher education governance. Higher Education, 62(5), 665-683. https://doi.org/10.1007/s10734-011-9412-4

Forsberg, K., Mooz, H., \& Cotterman, H. (2000). Visualizing Project Management. John Wiley \& Sons Inc.

Iegorchenkov, O. V., Lisitsyn, O. B., \& Kataev, D. S. (2012). Optimization of information management in product design management system. Management of Complex Systems, 13, 28-31.

Mazur, I. I., Shapiro, V. D., \& Olderogge, N. G. (2001). Project Management. Textbook for universities. Moscow: ZAO Publisher Economy.

Pherali, T. J. (2012). Academic mobility, language, and cultural capital: The experience of transnational academics in British higher education institutions. Journal of Studies in International Education, 16(4), 313-333. https://doi.org/10.1177/1028315311421842

Qiang, Z. (2003). Internationalization of higher education: Towards a conceptual framework. Policy Futures in Education, 1(2), 248-270. https://doi.org/10.2304/pfie.2003.1.2.5

Ramirez, G. B. (2014). A world of brands: Higher education and the emergence of multinational quality franchises. Quality in Higher Education.

Scott, P., Vlasceanu, L., \& Wilson, L. (Eds.). (n.d.). European higher education at the crossroads: Between the Bologna process and Springer: Netherlands Wilson, national reforms (pp. 377-386).

Streitwieser, B. (2014). Internationalization of Higher Education and Global Mobility. Oxford, UK: Symposium Books.

Teichler, U. (2009). Internationalization of higher education: European experiences. Asia Pacific Education Review, 10(1), 93-106. https://doi.org/10.1007/s12564-009-9002-7

Tesla, J. M., Inosova, S. V., Timinskyy, O. G., \& Iegorchenkov, O. V. (2010). Interpretation and use of the uncertainty principle in project management. Management of Complex Systems, 3, 33-36.

Van der Hijden, P. (2012). Student mobility in Europe: Recent trends and implications of data.

Wells, A. (2014). International student mobility: Approaches, challenges and suggestions for further research. Procedia-Social and Behavioral Sciences, 143, 19-24. https://doi.org/10.1016/j.sbspro.2014.07.350 


\section{Copyrights}

Copyright for this article is retained by the author(s), with first publication rights granted to the journal.

This is an open-access article distributed under the terms and conditions of the Creative Commons Attribution license (http://creativecommons.org/licenses/by/4.0/). 